http://jmscr.igmpublication.org/home/ ISSN (e)-2347-176x ISSN (p) 2455-0450 crossref DOI: https://dx.doi.org/10.18535/jmscr/v8i1.62

Journal Of Medical Science And Clinical Research

\title{
A Clinical, Biochemical and Immunological Profile of Systemic Lupus Erythematosus in Adult Patients in a Tertiary Care Centre
}

\author{
Authors \\ Dr Varsha Bhatt, Dr Mitali Khadke*, Dr Arjun Kakrani, Dr Love Garg, \\ Dr Manaswini Edara
}

Department of General Medicine Dr. D. Y. Patil Medical College, Hospital and Research Centre, Pimpri,

Pune, India

*Corresponding Author

Dr Mitali Khadke

\begin{abstract}
Background: Systemic Lupus Erythematosus [SLE] is an autoimmune disease. Autoantibodies can be present in many patients for a few years before the 1st clinical symptom appears. Considerable variation has been observed regarding various clinical manifestation of SLE among various ethnic groups as well as various geographical regions. This study was done to elucidate, clinical presenting features and various systemic manifestations, the biochemical parameters, inflammatory markers and immunological profile of the adult SLE in patients presenting to medicine wards of tertiary care centre.

Methods: All the adult SLE patients aged 18 years and above attending medicine OPD or admitted in Department of General Medicine during the study period from September 2017 to August 2019were included in the study.

Results: In the present study, male:female ratio was 21:1 with most common age group being affected was between 25-44 years. Musculoskeletal system (66.66\%) followed by mucocutaneous system (64.44\%) were most common systems affected in this study. 23(51.11\%) patients had organ threatening lupus affecting kidney and brain. Out of these 23 patients, 43.4\% didn't have mucocutaneous or musculoskeletal involvement at all which posed diagnostic challenge. ANA was positive in all patients. Anti dsDNA was commonest autoantibody found in this study. According to SLEDAI, 44.4\% patients presented with severe flare.

Conclusion: The majority of patients belonged to age group of 25-44 years with a female predilection and ANA was positive in all patients. Out of 23 patients which had major organ involvement at presentation $43.4 \%$ didn't have mucocutaneous or musculoskeletal involvement at all.

Keywords: SLE, lupus nephritis, neuropsychiatric lupus.
\end{abstract}

\section{Introduction}

Systemic Lupus Erythematosus [SLE] is an autoimmune disease in which damage to organs and cells initially mediated by tissue binding autoantibodies and immune complexes.
Autoantibodies can be present in many patients for a few years before the 1 st clinical symptom appears. Susceptibility is same for people of all genders, ages, and ethnic groups.SLE is more common in females as compared to males, 
especially in child bearing age group with a ratio ranging from $7: 1$ to $15: 1$ due to the role of estrogen in etiopathogenesis of disease. Considerable variation has been observed regarding various clinical manifestation of SLE among various ethnic groups as well as various geographical regions. As SLE is a multisystem disorder affecting all major organs and can be life threatening if it affects kidney and brain. Dermatological or skin manifestation can be very disfiguring. Some patients present only with internal organ manifestations such as nephritis and nervous system manifestations, which poses a diagnostic challenge. This study was done to elucidate, clinical presenting features and various systemic manifestations, the biochemical parameters, inflammatory markers and immunological profile of the adult SLE in patients presenting to medicine wards of tertiary care centre.

\section{Methodology}

Total no of 45 adult SLE patients fulfilling SLICC criteria attending OPD or admitted in Dr. D.Y. Patil Medical College and Hospital, Pune during the study period of September 2017 to August 2019 were selected. Institutional ethics committee approval was taken. A written, informed consent was taken from each patient before inclusion.

Inclusion criteria: 45 patients fulfilling the 2012 SLICC classification criteria for SLE coming to medicine OPD and wards, aged $\geq 18$ years.

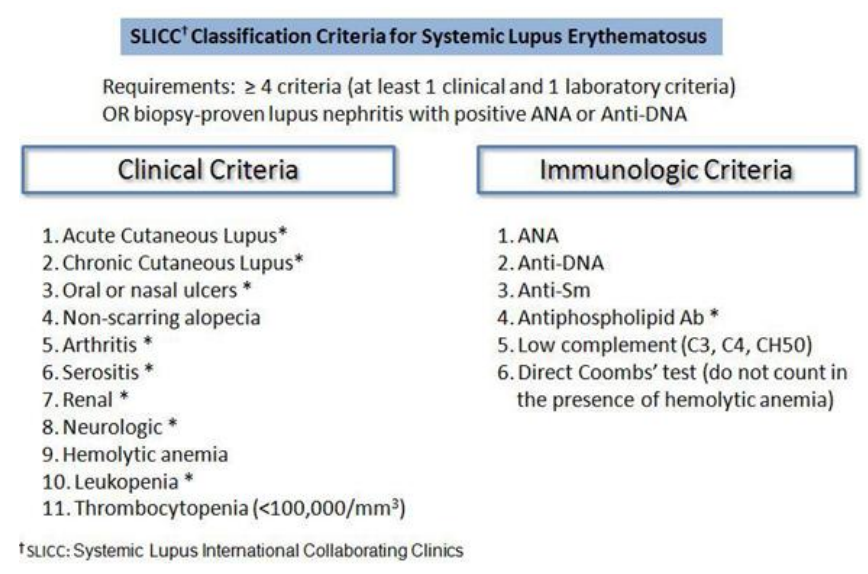

Figure 1: Classification criteria for system lupus Erythematosus.

\section{Exclusion Criteria}

- Rheumatoid arthritis and seronegative arthropathy group.

- Other connective tissue disease such as Systemic sclerosis (SSc), Primary Sjogrens syndrome (SS), Mixed connective tissue disease (MCTD), Polymyositis and dermatomyositis (PM/DM ) or overlap of SLE and any other disease.

- Vasculitis group.

- Undifferentiated connective tissue disease which does not fulfil criteria of SLE fully (UCTD).

\section{Procedure}

A complete history with presenting features were recorded and thorough physical examination was done. Involved joints were counted and evaluated. Number of tender and swollen joints were examined and range of motion seen. Skin and oral features was seen in detail and cutaneous features classified. All systems were examined in detail. Routine investigations such as hemogram, renal function test (RFT), liver function test (LFT), serum protein, urine routine and microscopy, urine protein creatinine ratio (UPCR) and 24 hours Urine protein were done and recorded in all patients. If found anemic, direct Coombs test was done. Inflammatory markers (erythrocyte sedimentation rate and $\mathrm{C}$ reactive protein), electrocardiography (ECG), x-ray chest (CXR), ultrasound (USG), and $2 \mathrm{D}$ Echo was done in all patients. Immunological markers such as ANA, ANA blot were done in all patients and reports recorded. ANA was done by either ELISA by Euroimmun ELISA kit or immunofluorescence assay, ANA blot by IMMUNOBLOT method on Euroline test kit. UPCR and 24 hours proteins by colorimetry. If pulmonary involvement was suspected, high resolution computed tomography (HRCT), 6 min walk test and diffusion capacity of carbon monoxide (DLCO) were done to evaluate lung involvement. Renal biopsy was done in indicated patients and findings and grade 
recorded. If suspected, antiphospholipid antibody (APLA) and complement levels were done. If required, as in Neurological manifestations, magnetic resonance imaging (MRI) or cerebrospinal fluid (CSF) was done.

Data Analysis: All qualitative and quantitative data was verified and compiled in Microsoft excel and Master chart was prepared.
Statistical Analysis: Data was entered into computer Microsoft Excel and exported to SPSS version 20 for analysis.

Continuous variables were expressed as mean \pm standard deviation or median and range. Categorical variables were expressed as frequency and percentage.

\section{Observations and Results}

Table 1: Distribution of SLE patients according to age groups and gender

\begin{tabular}{|l|c|c|c|c|c|c|}
\hline Age Group & $\begin{array}{c}\text { No. of } \\
\text { female } \\
\text { patients }\end{array}$ & $\begin{array}{c}\text { Percentage of } \\
\text { female patients }\end{array}$ & $\begin{array}{c}\text { No. of } \\
\text { male } \\
\text { patients }\end{array}$ & $\begin{array}{c}\text { Percentage } \\
\text { of male } \\
\text { patients }\end{array}$ & $\begin{array}{c}\text { Total no } \\
\text { of } \\
\text { patients }\end{array}$ & $\begin{array}{c}\text { Percentage } \\
\text { of total } \\
\text { patients }\end{array}$ \\
\hline 15-24 years & 9 & 20 & 1 & 2.22 & 10 & 22.22 \\
\hline 25-34 years & 13 & 28.88 & 1 & 2.22 & 14 & 31.11 \\
\hline 35-44 years & 14 & 31.11 & 0 & 0 & 14 & 31.11 \\
\hline 45-54 years & 3 & 6.66 & 0 & 0 & 3 & 6.66 \\
\hline 55-64 years & 2 & 4.44 & 0 & 0 & 2 & 4.44 \\
\hline 65-74 years & 2 & 4.44 & 0 & 0 & 2 & 4.44 \\
\hline
\end{tabular}

This table shows age of patients in this study varied from 18-68 years and most common age group of presentation was between $25-44$ years and mean was $33.9 \pm 11.5$.

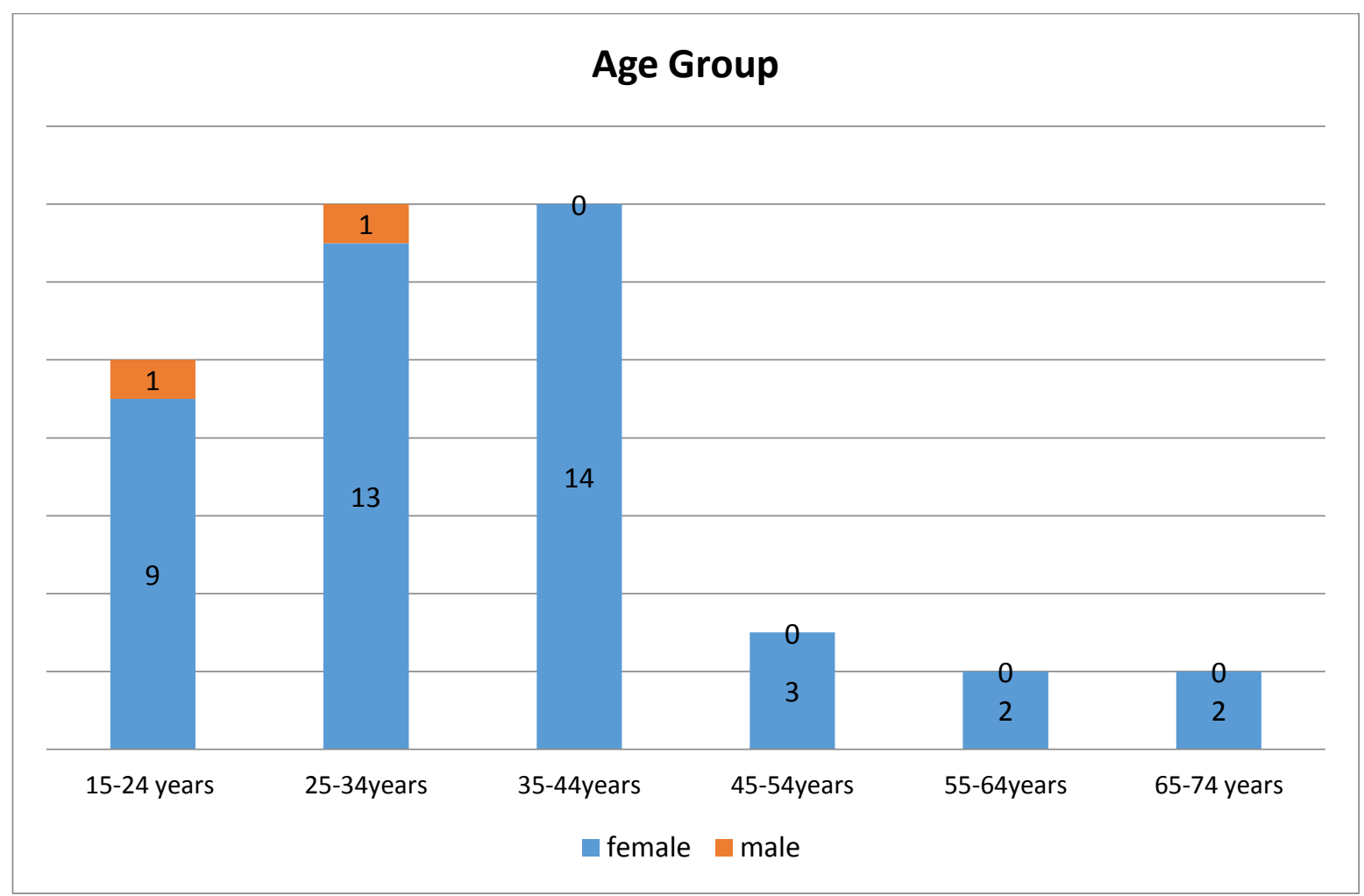

Graph 1: Distribution of SLE patients according to age groups and gender 
Table 2: Presenting clinical features

\begin{tabular}{|l|c|c|}
\hline Presenting features & No. of patients & Percentage of patients \\
\hline Cutaneous Rash & 27 & 60 \\
\hline Oral ulcers & 12 & 26.66 \\
\hline Vasculitic ulcers & 3 & 6.66 \\
\hline Alopecia & 14 & 31.11 \\
\hline Arthritis & 30 & 66.66 \\
\hline Photosensitivity & 26 & 57.77 \\
\hline Fever & 7 & 15.55 \\
\hline Facial puffiness/ pedal oedema & 10 & 22.22 \\
\hline Diarrhea/vomiting/abdominal pain/ & 5 & 11.11 \\
\hline Seizures & 3 & 6.66 \\
\hline Headache & 1 & 2.22 \\
\hline Hemiparesis/Quadriparesis & 3 & 6.66 \\
\hline $\begin{array}{l}\text { Breathlessness/ palpitations/ chest } \\
\text { pain }\end{array}$ & 4 & 8.88 \\
\hline
\end{tabular}

This table shows arthritis (66.66\%) followed by cutaneous rash(60\%) was most common presenting feature in this study.

Table 3: Systems involved in SLE

\begin{tabular}{|l|c|c|}
\hline Systems Involved & No. of patients & Percentage of patients \\
\hline Mucocutaneous & 29 & 64.44 \\
\hline Musculoskeletal & 30 & 66.66 \\
\hline Cardiopulmonary & 6 & 13.33 \\
\hline Renal & 15 & 33.33 \\
\hline Gastrointestinal & 0 & 0 \\
\hline CNS/PNS & 8 & 17.77 \\
\hline Hematological & 17 & 37.77 \\
\hline
\end{tabular}

This table shows musculoskeletal system(66.44\%) followed by mucocutaneous system(64.44\%) were most common systems involved in this study. $33.33 \%$ patients had renal involvement and $17.77 \%$ patients had CNS involvement.

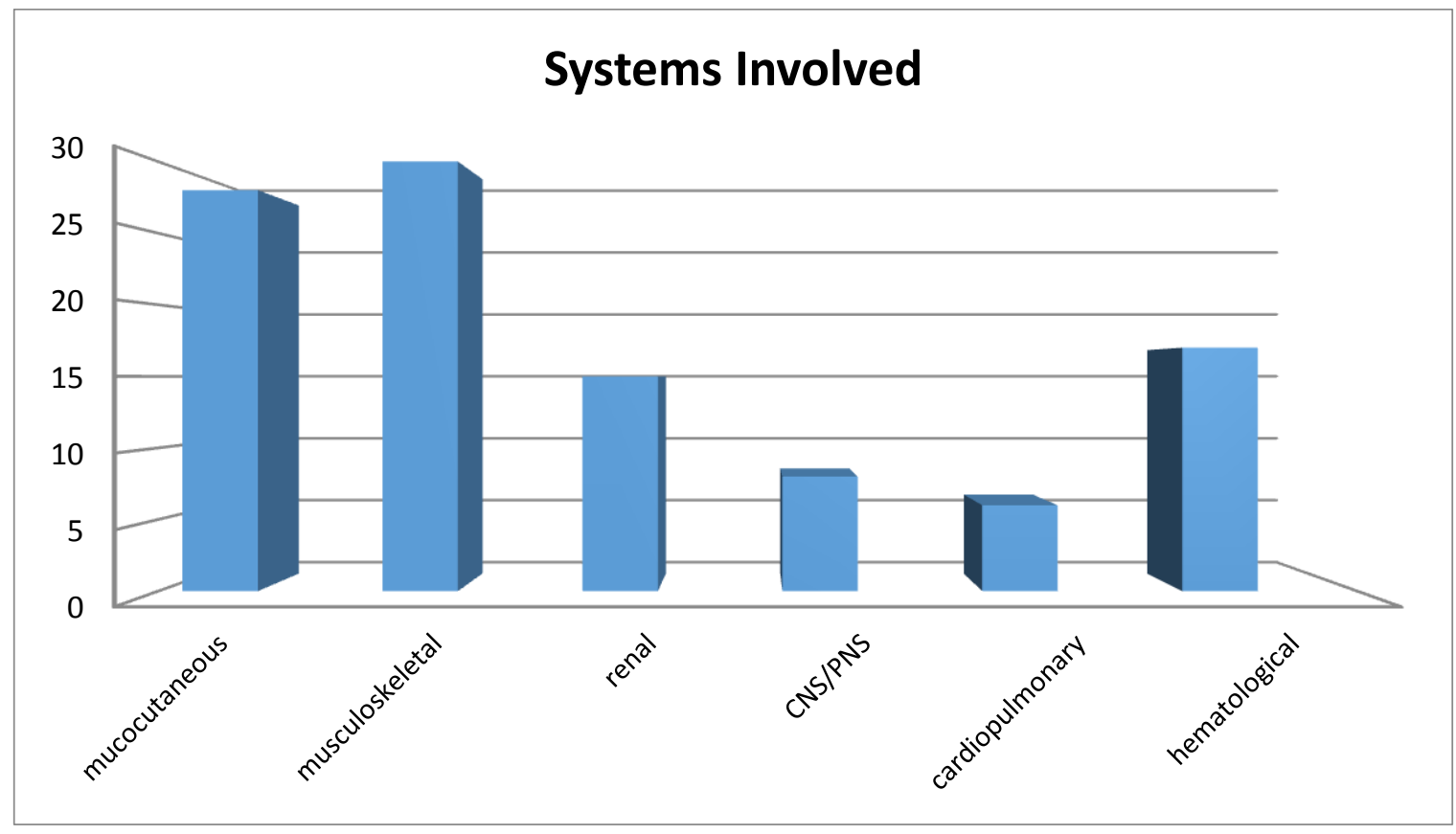

Graph 2: Systems involved in SLE 
Table 4: Types of skin rash in SLE

\begin{tabular}{|l|l|c|c|}
\hline \multicolumn{2}{|l|}{ Rash } & No. of patients & Percentage of patients \\
\hline ACLE & TEN & 1 & 2.22 \\
\hline & Bullous & 2 & 4.44 \\
\hline & malar & 20 & 44.44 \\
\hline SCLE & 1 & 2.22 \\
\hline DLE & 1 & 2.22 \\
\hline \multicolumn{2}{|l|}{ More than one type of rash } & 2 & 4.44 \\
\hline \multicolumn{2}{|l|}{ Total no of patients } & 27 & 60 \\
\hline
\end{tabular}

This table shows among cutaneous rash ACLE was most common type of rash.

Table 5: CNS manifestations in SLE

\begin{tabular}{|l|c|c|c|}
\hline CNS involvement & $\begin{array}{c}\text { No. of } \\
\text { patients }\end{array}$ & $\begin{array}{c}\text { Percentage out of } \\
\text { total no of patients }\end{array}$ & $\begin{array}{c}\text { Percentage out of total no of } \\
\text { neuropsychiatric lupus patients }\end{array}$ \\
\hline Seizures & 3 & 6.66 & 37.5 \\
\hline Stroke Venous & 3 & 6.66 & 37.5 \\
\hline $\begin{array}{l}\text { Cerebral } \\
\text { Thrombosis }\end{array}$ & 1 & 2.22 & 12.5 \\
\hline $\begin{array}{l}\text { Other- } \\
\text { multiplex mononeuritis }\end{array}$ & 1 & 2.22 & 12.5 \\
\hline Total no of patients & 8 & 17.77 & 100 \\
\hline
\end{tabular}

This table shows among patients with neuropsychiatric lupus, seizures and stroke were most common presenting features.

Table 6: Urine routine and microscopy findings

\begin{tabular}{|c|c|c|c|}
\hline \multicolumn{2}{|l|}{ Urine analysis } & No. of patients & Percentage of patients \\
\hline \multicolumn{2}{|l|}{ RBCs present } & 15 & 33.33 \\
\hline \multicolumn{2}{|l|}{ WBCs present } & 9 & 20 \\
\hline \multicolumn{2}{|l|}{ Casts present } & 0 & 0 \\
\hline \multicolumn{2}{|l|}{ Proteins present } & 15 & 33.33 \\
\hline \multirow{3}{*}{$\begin{array}{l}24 \text { hours urine } \\
\text { proteins }\end{array}$} & $<0.5 \mathrm{gm} / \mathrm{day}$ & 30 & 66.66 \\
\hline & $0.5-3.5 \mathrm{gm} /$ day & 11 & 24.44 \\
\hline & $>3.5 \mathrm{gm} / \mathrm{day}$ & 4 & 8.88 \\
\hline
\end{tabular}

This table shows total 15 patients had proteinuria. Out of these 15 patients, 4 patients presented with nephrotic range of proteinuria.

Table 7: ANA methods

\begin{tabular}{|c|c|c|c|c|}
\hline \multicolumn{3}{|l|}{ ANA Method } & No. of patients & Percentage of patients \\
\hline \multicolumn{3}{|l|}{ ANA by ELISA } & 38 & 84.44 \\
\hline \multirow{9}{*}{$\begin{array}{l}\text { ANA } \\
\text { Immunofluorescence }\end{array}$} & \multirow[t]{4}{*}{ Titers } & $1+$ & 3 & 6.66 \\
\hline & & $2+$ & 2 & 4.44 \\
\hline & & $3+$ & 2 & 4.44 \\
\hline & & Total by IF & 7 & 15.55 \\
\hline & \multirow[t]{5}{*}{ Patterns } & Homogenous & 5 & 11.11 \\
\hline & & Speckled & 2 & 4.44 \\
\hline & & Peripheral & 0 & 0 \\
\hline & & Nucleolar & 0 & 0 \\
\hline & & Centromere & 0 & 0 \\
\hline \multicolumn{3}{|c|}{ Total no of ANA positive patients } & 45 & 100 \\
\hline
\end{tabular}

This table shows ANA was positive in all 45 patients. ANA by ELISA was done in 38 patients and by immunofluorescence in 7 patients. 
Table 8: ANA profile

\begin{tabular}{|l|c|c|}
\hline ANA Profile & No. of patients & Percentage of patients \\
\hline Anti dsDNA & 29 & 64.44 \\
\hline Anti sm & 22 & 48.88 \\
\hline Ro52 & 16 & 35.55 \\
\hline SSA & 16 & 35.55 \\
\hline SSb & 2 & 4.44 \\
\hline Anti-histones & 8 & 17.77 \\
\hline nuclearRNP & 3 & 6.66 \\
\hline Nucleosome & 11 & 24.44 \\
\hline U1RNP & 15 & 33.33 \\
\hline ribP & 12 & 26.66 \\
\hline
\end{tabular}

This table shows Anti dsDNA was most common antibody found to be positive.

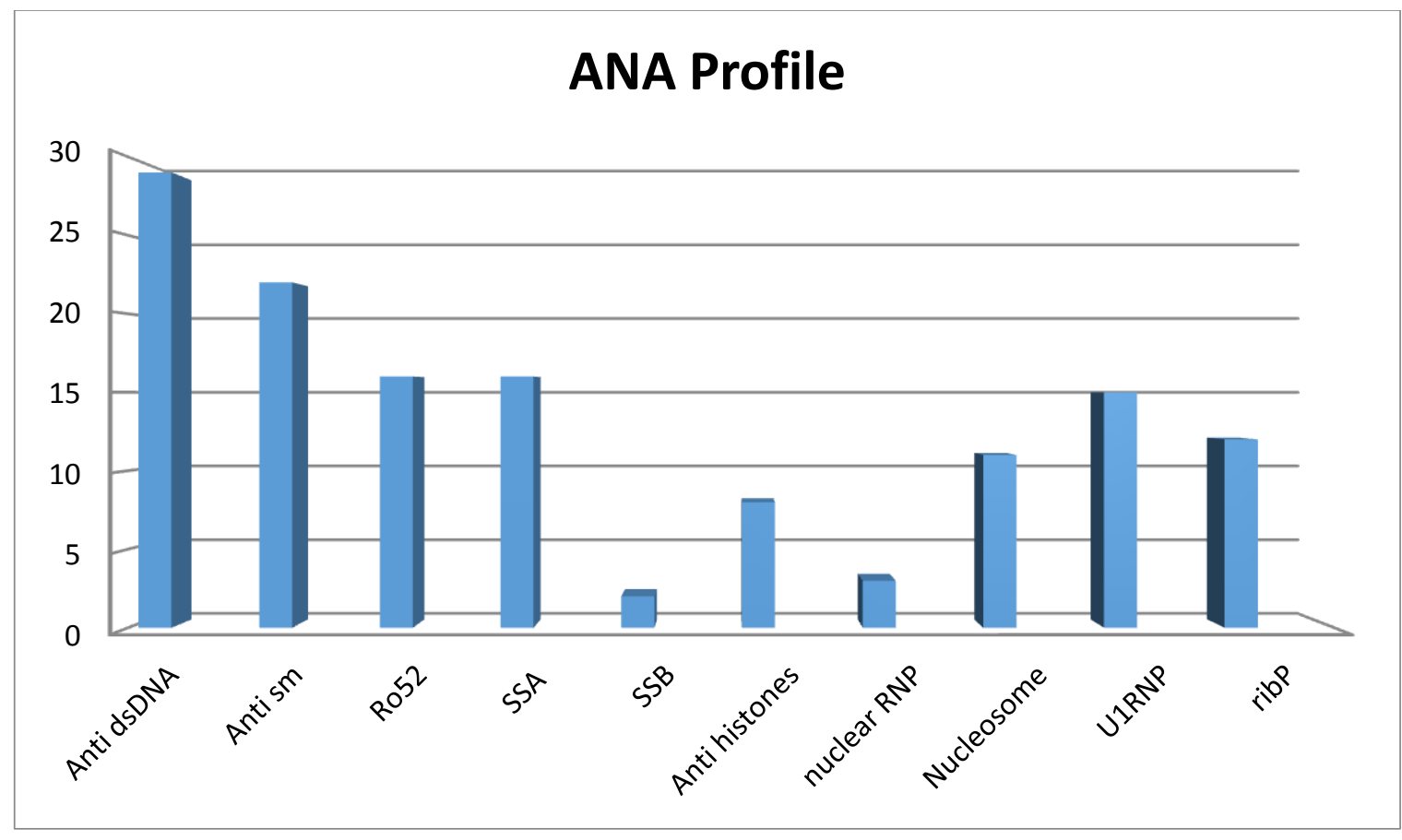

Graph 3: ANA profile

\section{Discussion}

The present study had total 45 patients out of which, 43 were females and 2 were males. Female to male ratio was $21: 1$. Binoy et $\mathrm{al}^{[1]}$ in India and LUMINA $^{[2]}$ cohort which is multiethnic US cohort suggested, females are affected more likely similar to the present study. Male patients had similar clinical profile as seen in females. Age of patients in this study varied from 18 to 68 years with mean age being $33.9 \pm 11.5$ years. Highest incidence was found in the age group of 25-34 and $35-44$ years. Binoy et al observed a mean age of disease onset at 21.6 years. The peak incidence rate of SLE in Birmingham, UK was reported between the ages of 18 and 19 years and in the USA was between the ages of 15 and 44 years. ${ }^{[3]}$
Musculoskeletal system (66.44\%) involvement is most common followed by mucocutaneous system $(64.66 \%)$ in the present study similar to studies done by Malaviya et $\mathrm{al}^{[4]}$, Madhavan et al, Mukherjee $\mathrm{S}$ et al in other parts of india. $87 \%$, $56 \%$ and $89.5 \%$ patients had musculoskeletal involvement in studies done by Cervera $\mathrm{R}$ et ${ }^{[5]} \mathrm{al}$ in Europe, Wong K.L. et al, ${ }^{[6]}$ and Al-Attia HM et $\mathrm{al}^{[7]}$ in middle east respectively.

Skin manifestation as initial presentation was seen in $29(64.44 \%)$ patients.

Most common were malar rash seen in $27(60 \%)$ patients and photosensitivity seen in $26(57.77 \%$ ) patients. TEN, bullous rash, SCLE, DLE type of rash were also seen in $2-4 \%$ of patients. oral ulcers $(26.66 \%)$, vasculitic ulcers $(6.66 \%)$, 
alopecia (31.11\%) were common skin manifestations seen in our study. Thus skin manifestations were the second most initial presentation seen in the present study. These findings are similar to studies done in other parts of india as well as in western countries.

Data from studies done in other countries shows higher incidence of renal involvement as initial manifestation compared to the present study. Compared to the present study which had $33.33 \%$ patients with renal involvement, Cervera $\mathrm{R}$ et al ${ }^{[5]}$, Wong K.L.et al, ${ }^{[6]}$ and Al-Attia $\mathrm{HM}$ et $\mathrm{al}^{[7]}$ showed $39 \%, 64.5 \%$ and $58 \%$ patients with renal involvement respectively. But study done by KC Maloney et $\mathrm{al}^{[8]}$ in Jamaica profiled only $16.7 \%$ patients with renal involvement which is lesser compared to the present study. Renal biopsy was done on Patients having proteinuria $>0.5$ grams/day i.e on 15 patients and they were found to be lupus Nephritis on Renal biopsy. Class III followed by class IV lupus nephritis were most common biopsy findings in the present study.

Among 45 patients, $17.77 \%$ patients had neuropsyciatric manifestations at the time of presentation. $6.66 \%$ patients presented initially as a young stroke and $6.66 \%$ patients had seizures at the time of presentation. One patient presented as cerebral venous sinus thrombosis who turned out to be SLE with negative APLA profile. One patient presented as a mononeuritis multiplex without mucocutaneous and musculoskeletal features at the time of presentation is also turned out to be SLE. $27 \%$ and $28.5 \%$ patients had CNS involvement in studies done by Cervera R et, AlAttia HM et al respectively at presentation.

Hematological manifestation as initial presentation was seen in 17 that is $37.77 \%$ of patients. $17.77 \%$ patients presented with leukopenia and $4.44 \%$ patients presented initially in form of Idiopathic thrombocytopenia. and $15.55 \%$ patients had both leukopenia and thrombocytopenia at the time of presentation. Haemolyticanaemia was seen in 8 to $14 \%$, patients in western countries and in 1 to $7 \%$ patients in India but in the present study nobody had haemolyticanaemia. $13.33 \%$ patients were having cardiopulmonary system involvement at the time of presentation. $6.66 \%$ were having myocarditis, $2.22 \%$ had arrhythmia and $4.44 \%$ had serositis. Cardiovascular involvement has been reported in 52 to $89 \%$ of patients in study by Brigden W et al ${ }^{[9]}$ and by Shearn M. A which is more as compared to the present study.

No patient has gastrointestinal involvement in the present study which was seen in 1 to $2.2 \%$ of patients in studies done by Malaviya et al' Madhavan et al.

A.N.A was positive in all 45 patients. ANA positivity was seen 96 and $98 \%$ of patients in studies done by Malaviya et al, Madhavan et al, which was $100 \%$ in the present study. Anti dsDNA was positive in $64.4 \%$ patients in the present study. Anti dsDNA was most common positive antibody seen in studies done by Malaviya et al and Madhavan et al which showed $55 \%$ and $65 \%$ patients with Anti dsDNA positivity respectively. Studies done in western countries also showed results which are similar to the present study that is ANA positivity in 95$96 \%$ of patients with SLE and anti dsDNA is most common positive antibody to be found in SLE patients.

\section{Conclusion}

In the present study, male:female ratio was 21:1 with most common age group being affected was between 25-44 years. Musculoskeletal system $(66.66 \%)$ followed by mucocutaneous system(64.44\%) were most common systems affected in this study.23(51.11\%) patients had organ threatening lupus affecting kidney and brain. Out of these 23 patients, $43.4 \%$ didn't have mucocutaneous or musculoskeletal involvement at all which posed diagnostic challenge. ANA was positive in all patients. Anti dsDNA was commonest autoantibody found in this study. 


\section{Abbreviations}

SLE- Systemic Lupus Erythematous

ANA- Anti Nuclear Antibody

ACR- American College Of Rheumatology

SLICC- Systemic Lupus International

Collaborating Clinics

APLA- Antiphospholipid Antibody

TEN- Toxic Epidermal Necrolysis

ACLE- Acute Cutaneous Lupus Erythematous

SCLE- Subacute Cutaneous Lupus Erythematous

DLE- Discoid Lupus Erythematous

\section{References}

1. Binoy JP, Muhammed F, Kumar N, Razia MV. Clinical profile of systemic lupus erythematosus in North Kerala. J Indian RheumatolAssoc 2003;11:94-7.

2. R. M. Andrade, G. S. Alarcón, M. Fernández, J. D. Reveille, and LUMINA Study Group, "Accelerated damage accrual among men with systemic lupus erythematosus: XLIV. Results from a multiethnic US cohort," Arthritis \& Rheumatism.2007:56 (2): 622-630

3. Johnson $\mathrm{AE}$, Gordon $\mathrm{C}$, Palmer RG, Bacon PA. The prevalence and incidence of systemic lupus erythematosus in Birmingham. Engl Arthritis Rheumatol. 1995;38(4):551-558..

4. Malaviya AN, Singh RR, Kumar A et al. SLE in Northern India. A review of 329 cases. J AssocPhys India 1988; 36: 47680.

5. Cervera $R$ et al. Systemic lupus erythematosus: clinical and immunological patterns of disease expression in a cohort of 1000 patients. Medicine (Balt.) 1993;72: 113-124.

6. Wong K.L. Pattern of SLE in Hong Kong Chinese: a cohort study. Scand J Rheumatol 1992; 21: 289-296.
7. Al-Attia HM, George S. Characterization of systemic lupus erythematosus in patients in UAE. Clinical Rheumatology; 14: $171-175$

8. Maloney, K. C., Ferguson, T. S., Stewart, H. D., Myers, A. A., De Ceulaer, K. Clinical and immunological characteristics of 150 systemic lupus erythematosus patients in Jamaica: a comparative analysis. Lupus.2017 26(13), 1448-1456.

9. Shearn MA. The heart in systemic lupus erythmatosus. Am Heart J 1959; 58:452466. 